Article

\title{
Technologies and Principles of Hot Recycling and Investigation of Preheated Reclaimed Asphalt Pavement Batching Process in an Asphalt Mixing Plant
}

\author{
Henrikas Sivilevičius, Justas Bražiūnas * (i) and Olegas Prentkovskis \\ Department of Mobile Machinery and Railway Transport, Faculty of Transport Engineering, \\ Vilnius Gediminas Technical University, Plytinès g. 27, LT-10105 Vilnius, Lithuania; \\ henrikas.sivilevicius@vgtu.lt (H.S.); olegas.prentkovskis@vgtu.lt (O.P.) \\ * Correspondence: justas.braziunas@vgtu.lt; Tel.: +370-612-18487
}

Received: 18 September 2017; Accepted: 23 October 2017; Published: 25 October 2017

\begin{abstract}
More and more recycled asphalt mixtures with high reclaimed asphalt pavement (RAP) content are used in road pavement. Having determined and evaluated RAP composition (aged bitumen content and aggregate gradation) and properties, a suitable recycling agent and virgin materials are selected in the design process. The gradation of hot mix asphalt (HMA) mixture that is recycled in an asphalt mixing plant (AMP) shall correspond to its optimal gradation set out in its job-mix formula (JMF). When RAP is recycled in an AMP, inevitable systematic and random errors of performed technological operations and inhomogeneity of virgin materials and RAP have a significant influence. These factors influence the variation of components quantities of recycled hot mix asphalt (RHMA) mixture and deviations from JMF. In this study, the principles of asphalt pavement hot recycling are systematized, which allows analysis of the factors of components' interaction influencing the results of the recycling process. The paper also presents and analyses asphalt recycling technologies in AMP and their comparative analysis. During the season of asphalt mixture production in 2014, statistical parameters were calculated according to the data obtained from one of the companies, which collected and systematized RAP batch masses, when before batching it was pre-dried and pre-heated in an additional dryer. These parameters of batch mass and RAP content in RHMA position and variation were used when evaluating the accuracy and precision of the recycling process in AMP. The obtained data showed that when RHMA mixtures are produced in a modern batch-type AMP, RAP is batched accurately, but not precisely enough.
\end{abstract}

Keywords: asphalt pavement; recycling principles; asphalt mixing plant (AMP); reclaimed asphalt pavement (RAP); batching errors

\section{Introduction}

Production of asphalt can incorporate reclaimed materials from the deconstruction of road surfaces. This aids in reducing production costs and saves natural resources, bitumen, and aggregates. However, recycling can only be justified if the performance and longevity of the produced pavement is equal or better than that of traditional mixtures. Mixtures containing RAP have not always demonstrated such performance. Premature cracking due to the aged bitumen is one of the main reasons that agencies are reluctant to increase allowed RAP content in the mixtures $[1,2]$. Another reported problem is the variability of RAP material, which does not allow to securely assume that the produced mixture properties will reflect laboratory design [3]. Finally, problems with production technology have been reported, including excessive emissions and issues with consistency of mixture that has resulted in poor pavement performance $[4,5]$. 
These reported problems, however, can be accounted for and the desired performance for mixes containing RAP can be ensured by taking comprehensive measures in three broad areas:

- Materials. It must be ensured that the reclaimed materials correspond to the requirements, they are homogeneous, with a low moisture content, and without contamination.

- Mix design should be performed according to best practices, depending on recycled asphalt content and its properties to ensure the reduction of stiffness of the aged binder, as well as the desired performance properties for the entire life-cycle of the pavement [6].

- The production technology must allow for incorporating the desired RAP content by heating it to the necessary temperature and ensuring homogeneous blending with virgin materials without creating emissions [7].

Most laboratory studies have demonstrated evidence that high RAP pavements can achieve the desired pavement performance and longevity that are equal to conventional asphalt [8-10]. Adequate mix design procedures can even allow for creating mixtures containing $100 \%$ recycled asphalt $[11,12]$. It has also been confirmed that adequate full-scale RAP management, production, and mix design procedures can lead to excellent field results. The research by [13,14] provides evidence that adequate management and processing of RAP can ensure homogeneity of RAP equal or better than that of virgin aggregates. A comprehensive study by National Center for Asphalt Technology (NCAT) [15] evaluated the long-term performance of 18 sites across North America with pavements containing 30\% RAP and concluded that the performance is similar to pavement constructed from virgin materials with no RAP. Thus, it becomes evident that both adequate design procedures and full-scale production technologies are currently available and allow for high RAP production [16]. So, why is it not being done routinely?

One of the reasons is that, although a lot of research is being done in laboratory, independent scientific research on production technologies and other full-scale operations and the means to improve them is scarce. This is likely because of the high research costs and many available (and constantly changing) technologies. At the same time, as reported by [17], a large portion of the failures of mixtures containing RAP have been caused by the "use of unprocessed RAP and hot-mix plants that were not designed to handle high RAP contents." Thus, a clear, full-scale research is necessary. The pavement performance is equally dependent on design procedures and consistent production and only adequate accounting for both of these factors can ensure satisfactory pavement performance [18].

This article aims to link different features of a full-scale production to allow for a theoretical evaluation of the entire production process chain. Only a comprehensive approach like this can permit analysing the "bottle necks", which preclude increasing the reclaimed asphalt content in the mixture or to find the defective link in the chain in the case of unsatisfactory performance of the pavement. Such an approach is also necessary when aiming at a cleaner production. The entire chain of operations must be analysed considering the long term consequences. This encompasses undertaking daily, weekly, and yearly analyses. This article will present the theoretical basis of the asphalt production chain and then focus on the asphalt production with regards to ensuring the desired mixture homogeneity.

The aim of the study is to present the analysis of mandatory actions of asphalt pavement hot recycling based on scientific principles and to investigate the parameters of technological operations, performed in batch AMP with additional RAP drying and heating.

\section{Theoretical Formulation of the Problem}

\subsection{Principles of Asphalt Pavement Hot Recycling}

When developing asphalt pavement recycling methods and technologies, the most important principles of this relatively new and promising method of recycling road pavement by reusing its asphalt materials shall be known and applied. We present these principles based on our personal 
theoretical knowledge and practical experience, as well the analysis of the findings of the investigations conducted by other researchers. The scheme of twelve principles is presented in Figure 1.

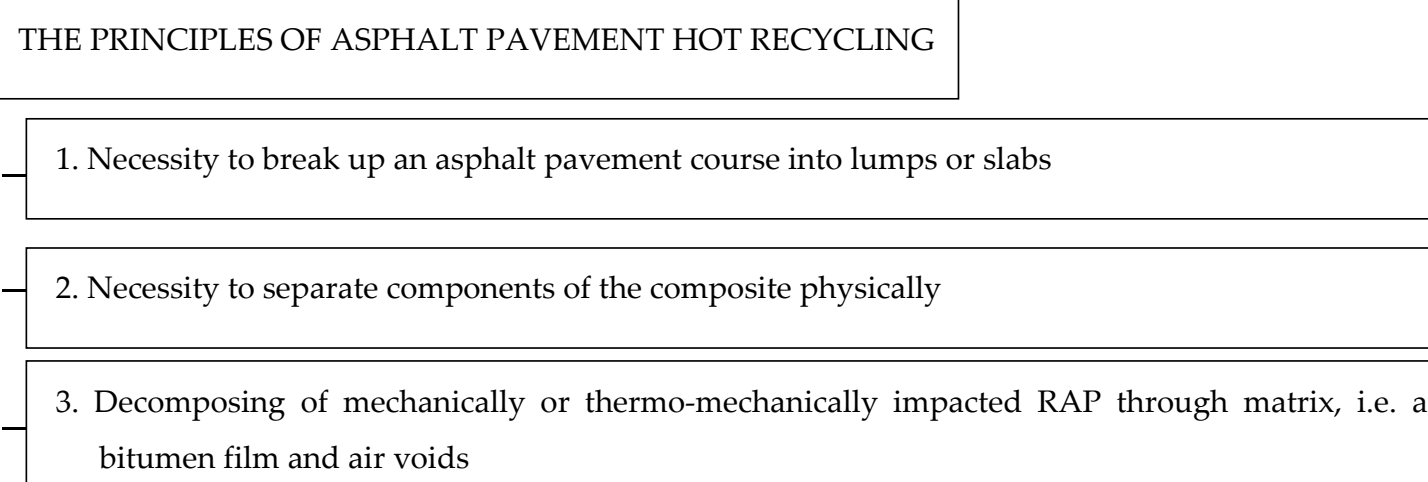

4. Not damaging the mineral components separable from each other and a bitumen binder

5. Water content removal from the recycled material of asphalt pavement

6. Necessity to blend mechanically: free or/and forced movement of separate components in space

7. Formation of the largest possible surface of aged bitumen films to be coated with a rejuvenator

8. Capability of a rejuvenator to coat all particles uniformly and to diffuse into aged bitumen films

9. Retardation of bitumen oxidized ageing inthe technological process of recycling

10. Failure to remove aged bitumen and/or some of the aggregate fractions from the recycled asphalt mixture

11. Compliance of the designed recycled hot mix asphalt (RHMA) quality indicators with the design specification requirements

12. Compliance of in-plant or in-place (on the road) recycled asphalt mixture composition and properties with the job-mix formula (JMF)

Figure 1. The system of scientific principles of asphalt pavement hot recycling.

The first principle (necessity to break up an asphalt pavement course into lumps, or slabs). The asphalt of the reclaimed pavement containing the matrix and inserts of the composite shall be mechanically, thermally, or hydrothermally crushed (broken-up) into separate components. This enables to improve its whole structure and properties by incorporating some materials, not only those in the surface course of the road pavement $[19,20]$. It is rather complicated and ineffective to 
incorporate rejuvenating additives into a compacted and dense pavement through air voids from the top. A ravelled aged asphalt course of the road pavement, which is not crushed into small particles, would not be uniformly recycledthroughout the whole thickness of the course.

The second principle (necessity to separate physically the components of the composite). The asphalt of the recycled pavement shall be downsized to its granular particles (RAP). Aggregate particles of different sizes (solid phase) are separated by breaking-up the films of the bitumen bonding them (liquid phase). As adhesion is stronger than cohesion, thermo-mechanically impacted RAP frequently decompose not only at the border of bitumen and particles, but in the course of volumetric bitumen and air voids. Particles are separated from each other in order that when they are changing their position in space, they allow rejuvenating agents (binder or/and mineral aggregates) to permeate through open gaps, which would distribute uniformly among the obtained particles of the recycled asphalt mixture [21].

The third principle (decomposing of mechanically or thermo-mechanically impacted RAP through matrix, i.e., a bitumen film and air voids). The RAP of aged pavement shall be broken up in order that the material that binds asphalt (the variation system of a bitumen binder and mineral fillers or volumetric bitumen films, which cement the composite material into a conglomerate) decomposed. During its recycling process, surfaces may merge with microcracks occurring in the aged road pavement and air voids. It would be desirable that the surfaces were formed in a matrix, not in inserts (coarse and fine aggregate), when asphalt decomposes (is milled, broken-up or crushed). In the contact zone of a milling machine cutter or a stone breaker (crusher) with reclaimed asphalt, new uncoated surfaces form when stone and fine aggregate particles split, which increases the area of all particles of the mixture and the necessary summative amount of the recycled bitumen. When asphalt pavement is cold-milled or its broken lumps or slabs are crushed in a stonebreaker, some coarse and fine aggregate particles inevitably split up (break up). When heated road pavement is milled with a mobile recycler, the probability of particle splitting decreases. If the degree of aged mineral aggregate fractioning is unknown and it is not taken into consideration when batching additional virgin mineral aggregates or an asphalt mixture, RHMA with a higher content of fine particles is obtained.

The fourth principle (not damaging the mineral components separable from each other and a bitumen binder). The methods and technologies of separating solidified and liquefied phases of asphalt pavement from each other shall ensure that aged bitumen and mineral particles are suitable for the use in a recycled asphalt mixture. Thermal weakening of the matrix (bitumen or asphalt binding material) by reducing the viscosity of aged bitumen before decomposing to the strength that is lower than that of inserts (particles of coarse and fine aggregate) decomposes reclaimed asphalt through matrix, not inserts, due to decreasing adhesion and cohesion. Splitting and crumbling of aggregate particles shall be avoided. When reclaimed asphalt is heated, the properties of aged bitumen should not worsen due to overheating. Usually, RAP that has been heated in the RAP channel goes to a hot RAP storage bin when it has reached its desired temperature $\left(100-120^{\circ} \mathrm{C}\right)$ at the end of circulation line. When it is stored in the bin, it will maintain a warm temperature. Chemical solvents that are used for bitumen recovery, but not for the improvement of its properties, are not suitable for separating the components of RAP from each other.

The fifth principle (water content removal from the reclaimed material of asphalt pavement). The RAP that was milled or crushed and sieved in a stonebreaker almost always contains a certain amount of water. It is likely to become a wet hot-in-place recycled asphalt pavement. When stockpiled, precipitation water increases the water content of this material. Therefore, it is recommended to store RAP that is prepared for use in a stockhouse or in a shelter. This water shall be removed by applying the laws of heat transfer in some equipment [22,23]. Wet and cold RAP, usually sized up to $32 \mathrm{~mm}$, can be dried and heated up in an AMP in the following two ways: first, cold RAP is mixed with superheated virgin mineral materials, takes over part of their heat, dries and heats up; second, RAP is heated up in a parallel additional dryer (in-dryer) using the heat that is radiated by the burner. When the road pavement is recycled with a mobile recycling equipment (hot-in-place 
recycling), it is heated up by infrared burners from the top [24]. When water films are removed from the surface of RAP particles and microcracks, the adhesion of the recycled summative (aged and virgin bitumen) bituminous binder and mineral aggregates increases, which influences the strength of the recycled asphalt.

The sixth principle (Necessity to blend mechanically: free or/and forced movement of separated components in space). All or most of the particles of different sizes of the reclaimed asphalt shall be separated from each other so that when mixed, they could change their position in relation to each other and their location in a mix or a flow. When during initial decomposition road pavement structure courses are cold-milled or flat asphalt lumps or their slabs (pieces) are crushed (pulverized), and particles are obtained. When granular asphalt is heated up during the second decomposition, viscosity, adhesion, and cohesion of the old bitumen are reduced. Therefore, when exposed to mixing forces weaker than those of milling, particles partially break up and mineral particles redistribute in space, thereby opening new unbound surfaces that could be exposed to rejuvenators (additives). When the heated-up asphalt pavement is milled or broken, and when the films of the reclaimed old liquefied bitumen binder melt sufficiently, adhesion (bonding of bitumen molecules with mineral particles) and cohesion (interaction of bitumen molecules) are reduced. This makes the separation of particles from each other easier and takes less mechanical power, but requires more heat.

The seventh principle (formation of the largest possible surface of aged bitumen films to be coated with a rejuvenator). Particles of granular mixture obtained from the heated-up, and the mixed RAP is coated with extremely viscous oriented inner bitumen films of a certain thickness with a higher content of asphaltenes [25]. Due to adsorption into open voids of particles and microcracks (splits), and due to stronger adhesion, they barely melt and decompose. These particles are also coated with outer bitumen films, which weakly interact with the surface of particles as they do not directly contact with them. Volumetric bitumen films make up an outer layer, in which the content of liquid tars and oils reduces during the road use. At the temperature lower than that of the oriented bitumen they melt and become a viscous liquid that can flow in separate drops and at the molecular level mix with the rejuvenators recycling the old bitumen or virgin more liquefied bitumen [26,27]. Volumetric bitumen films oil the surfaces of mobile particles and facilitate the mixing process of the recycled asphalt mixture. When mixing the recycled asphalt mixture, more and more new surfaces of aged particles, which can absorb the batched rejuvenators or a virgin liquefied bitumen, open [28,29]. It takes more energy for finer particles to separate from each other. If they are not separated, rejuvenators, which improve aged bitumen, cannot pass and part of the mixture remains unrecycled.

The eighth principle (capability of a rejuvenator to coat all particles uniformly and to diffuse into aged bitumen films). The rejuvenators improving the properties of the aged bitumen in the recycled asphalt mixture shall uniformly distribute on the surface of each mineral particle, coated with oriented and volumetric bitumen films $[7,30]$. The thickness of a newly formed film of the rejuvenator shall ensure that upon completion of its diffusion into the double coating of aged bitumen, the properties of its summative bitumen are restored to the appropriate structure and properties of the recycled asphalt mixture. The deeper that a rejuvenator or a virgin bitumen penetrates into the double-coating system of reclaimed bitumen films due to diffusion after the technological process of recycling, the more complete this process is and the less asphalt properties change in the beginning of its exploitation [31-33]. The long duration of the diffusion of the rejuvenator into aged bitumen does not allow the consideration of the process of asphalt recycling as complete [34]. The duration of diffusive mixing of reclaimed old and virgin bitumen in films should be as short as possible, as only upon completion of this process the new structure of the recycled asphalt structure forms and its required (rated) resilience is obtained. Classically approach, Fick's law and Arrhenius equation describes this theory [33].

The ninth principle (retardation of bitumen oxidized ageing in the technological process of recycling). When the aged structure decomposes at high temperature of asphalt recycling process, unbound surfaces of aged volumetric bitumen contact with ambient air. The components of aged 
bitumen intensively oxidize and vapour even more due to ageing, thereby worsening the properties of summative bitumen $[35,36]$. Therefore, the temperature of the recycled asphalt mixture should not be too high and the duration of works should not be too long. When stored in a silo of an AMP and transported in a truck for a considerable period of time, laid, and compacted slowly, the structure and properties of the hot-recycled asphalt mixture deteriorate.

The tenth principle (failure to remove aged bitumen and/or some of the aggregate's fractions from the recycled asphalt mixture). The gradation of aggregates in an asphalt mixture complies with a certain optimal content of bituminous binder, which ensures its best properties [37]. When reclaimed asphalt is being recycled, the properties of aged bitumen are improved by admixing a rejuvenator or virgin bitumen, which always increases the content of summative bitumen and makes it not optimal. In order to optimize the content of summative bitumen, aggregates of appropriate fractions shall be added [38]. It is practically impossible to remove aged bitumen and (or) some aggregate fraction from recycled asphalt. It is possible only to add rejuvenators. Virgin mineral aggregates, which improve the gradation absorb part of the aged volumetric bitumen, transferring from the surface of the granular particles of reclaimed asphalt (during hot-in-plant recycling). When asphalt pavement is hot-in-place recycled with a mobile Remixer, the particles of additional HMA mixture are coated with virgin bitumen and transfer part of it to aged particles. It is likely that during the mass exchange process, aged bitumen is transferred to new particles of an additional HMA mixture. This way, a reversible double coating of new particles is obtained: exogenous coating of aged bitumen and indigenous coating of new bitumen films. These two different hot recycling technologies impact on the different formation of the structure of double-coating of a bitumen film, which coats aged and virgin particles, the thickness of the coatings, diffusion processes, and the properties of the recycled asphalt.

The eleventh principle (compliance of the designed RHMA quality indicators with the design specification requirements). RHMA is designed using the RAP, virgin mineral aggregates, virgin bitumen, or any other rejuvenator, when their factual properties and composition are identified and evaluated. The proportion of virgin bituminous binding materials and aggregates is selected taking into account the composition of RAP, its homogeneity and the properties of aged bitumen [39-41]. The aim is to obtain such physical and mechanical properties of RHMA, which are not worse than those of the mixtures made of purely virgin materials (for mixtures of the mix group) and the type of bituminous mixture and which comply with the specifications set out in European Standart (norm) EN 13108-1, ..., EN 13108-7 and EN 13108-20. The lower the homogeneity of RAP is, the less amount of it can be batched in the manufactured recycled HMA mixture [42]. RAP homogeneity is evaluated according to EN 13108-20 and TRA ASFALTAS 08.

The twelfth principle (compliance of in-plant or in-place recycled asphalt mixture composition and properties with the JMF). The recycled hot bituminous mixture manufactured from RAP and virgin materials in an AMP or in a mobile Remixer shall meet Factory Production Control requirements, as specified in EN 13108-21. Therefore, the errors of technological parameters are minimized during the recycling process, which enables to deviate the factual composition of the recycled HMA mixture, temperature, physical, and mechanical indicators from the JMF within permitted (tolerance) limits [43].

\subsection{Model of Technologies of RAP Recycling}

Such asphalt pavement recycling principles are entirely or partially applied in hot-mix recycling process of RAP in an AMP. The recycling process may be divided into sequential technological operations (Figure 2).

In conventional AMP constructed to recycle aged RAP, additional technological equipment to feed, store, supply (transport), batch, dry, heat up, and mix RAP with virgin materials be used (Figure 3). Recently, the increasing content of RAP has been observed. The structure of the equipment designed to recycle RAP depends on the maximum permitted RAP percentage content, the methods of drying and heating up, the place of batching in AMP, as well as mixing with virgin materials. When a small percentage (up to $10 \%$ or $20 \%$ of RAP content from the total mass of recycled asphalt mixture) is used, 
a batch-type AMP without additional heating of RAP is the most suitable one (Figure 3D). AMP of this type enables the delivery RAP into its four types of equipment: 1 -hot elevator; 2 -hot aggregate bin (compartment of bypass); 3-hot aggregate scale bin; and, 4-mixer. To batch the increased RAP percentage content (from $20 \%$ to $50 \%$ ), it is dried and heated up in an additional cylinder dryer, incorporated into a batch-type AMP (Figure 3C).

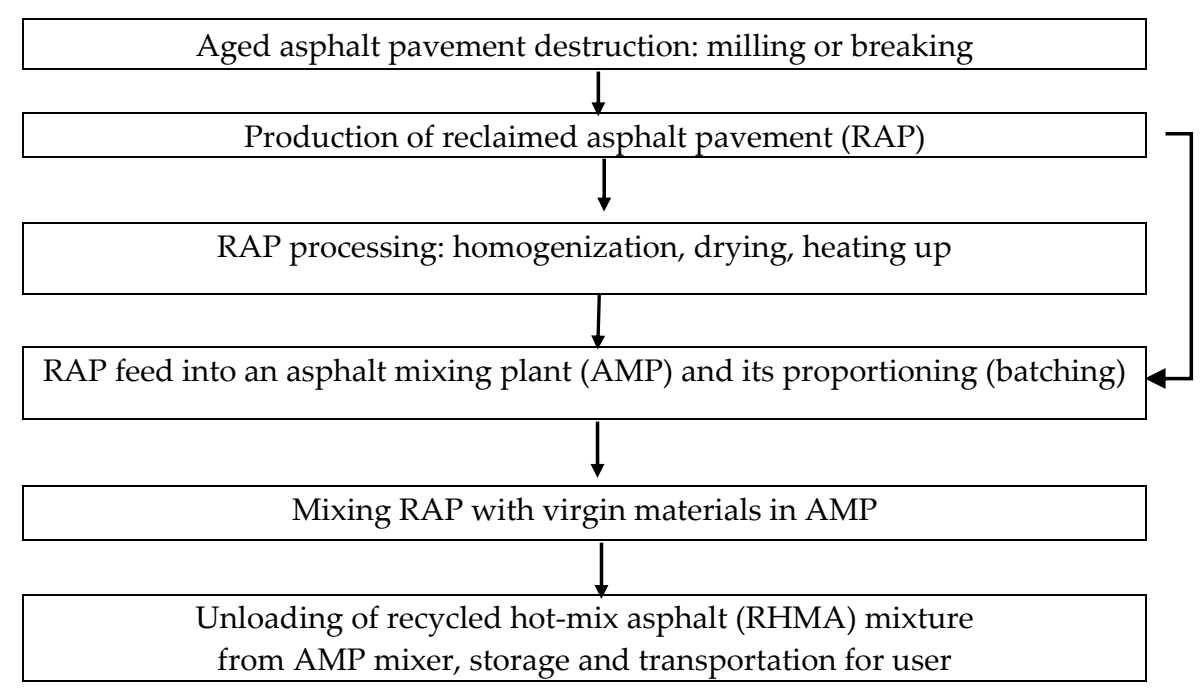

Figure 2. Production operations of the in-plant recycling process of aged asphalt pavement.

RAP can also be recycled in a continuous AMP with integrated drum-mix (Figure 3A) or double barrel dryers-mixers (Figure $3 \mathrm{~B}$ ). When using this equipment, $50 \%$ or more of wet and cold particles of RAP could be batched. All of the asphalt recycling technologies presented in Figure 3 have both advantages and disadvantages.

Recent theoretical and practical achievements enable the recycling of up to $100 \%$ of RAP, of course, we need to evaluate that the studies were conducted in ideal and lab-controlled conditions $[44,45]$. RAP inhomogeneity has a huge impact on its maximum permitted percentage in a recycled RHMA. It is only in rare cases that RAP is sieved into two or more different size fractions. A lack of an efficient practical method, which enables to homogenize RAP prepared for use, does not allow the use of high RAP content in a recycled hot-mix asphalt (RHMA) mixture. As a rule, according to the standards it is allowed use less RAP content in a recycled asphalt mixture of the pavement surface course than in a binder or a base course [42].

When RHMA mixture is produced in an AMP, cold and wet RAP is dried and heated up to break them down into separate component particles, which could absorb thin films of a rejuvenator on their surface. RAP may dry out and heat up in two technological ways of heat transfer: first, (Figure 3A,B,D technologies) without preheating the reclaimed material [46], when RAP take over some of the heat of aggregates (superheated virgin materials, superheating temperature) in contact with superheated aggregates; second, (Figure $3 \mathrm{C}$ technology) the flow of RAP is dried and heated up (up to $100-110{ }^{\circ} \mathrm{C}$ ) in a separate parallel dryer, where a mixture of heated up gas and air is emanated from a burner [47].

The most important technological requirements for the production of RHMA mixtures are as follows:

- the conformity of its gradation (content of mineral filler, fine aggregate and coarse aggregate and bituminous binder content with JMF; and,

- the conformity of the RHMA mixture temperature to the type of used bituminous binder grade. 


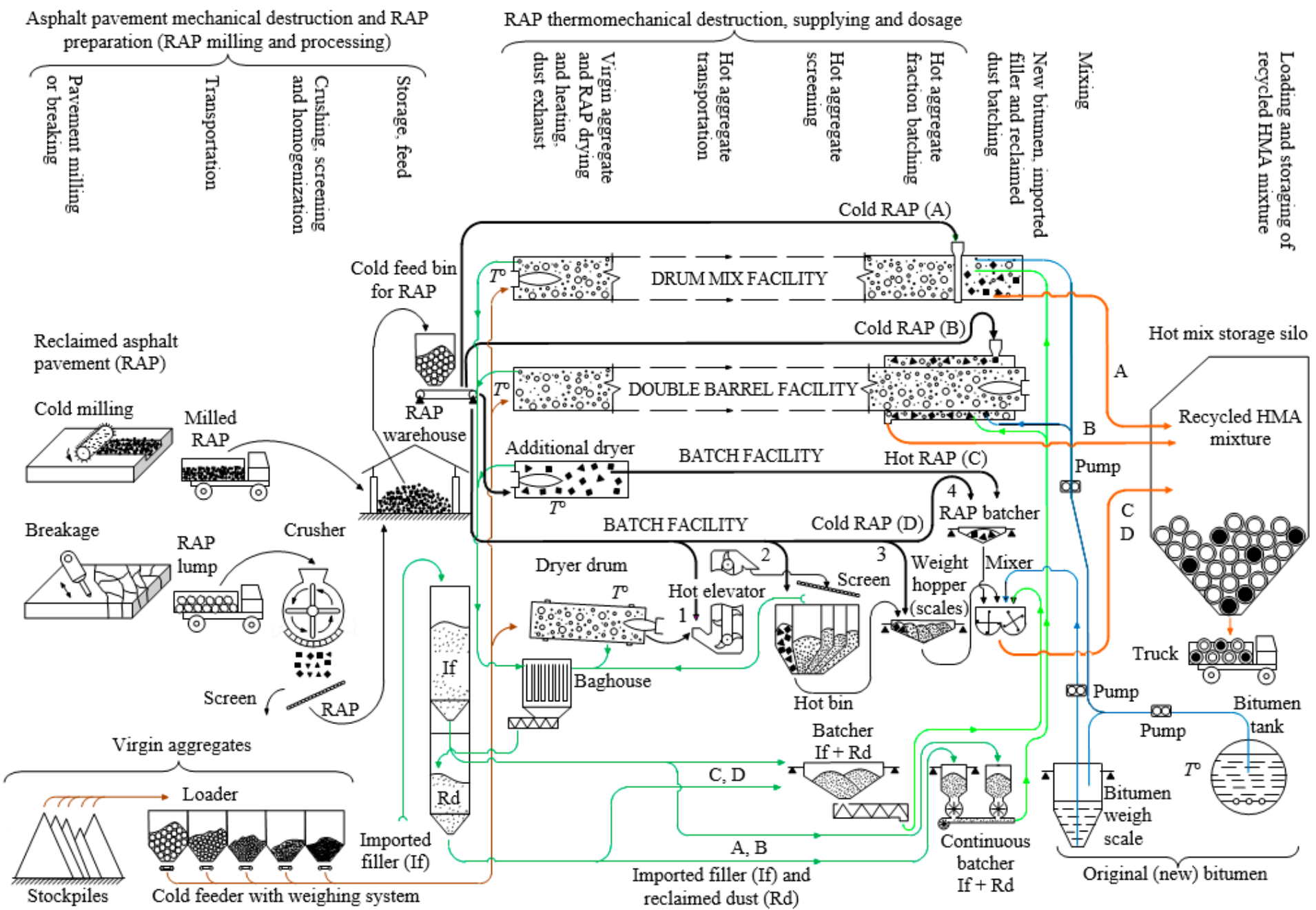

Figure 3. The model of asphalt pavement recycling operations and equipment used in batch plant (C,D), drum mix (A) and a double barrel-drum mix (B) when reclaimed asphalt pavement (RAP) is supplied and dosed to different places. 
Technical requirements TRA ASFALTAS 08 drafted in compliance with the above-mentioned standards requires that the max allowed content of RAP $K_{i}$ should be calculated according to Equations (1) and (2) taking into account the homogeneity of RAP. Such homogeneity is determined by the range indicators for individual properties $\left(a_{i}\right)$. $K_{i}$ shall be computed by the general permissible deviations $N_{a d m, i}$ depending on the property of RAP and the type of recycled HMA mixture:

$$
K_{i}=\frac{0.50 N_{a d m, i}}{a_{i}} \times 100
$$

or

$$
K_{i}=\frac{0.33 N_{a d m, i}}{a_{i}} \times 100,
$$

where $a_{i}$ is the range between the max $x_{i, \max }$ and the $\min x_{i, \min }$ values of RAP $i$-property indicator estimated for the sample ( $\min$ sample size $n=5$ ).

With respect to all of the properties of base and surface-base course mixtures, Equation (1) shall apply. It shall be also applied for the softening point of binder course and surface course mixtures. With respect to all other properties, Equation (2) shall apply [42].

RAP is not only homogeneous, but it is also dosed with systemic and random errors of a certain magnitude in the AMP that increase the deviations of the RHMA component content from JMF and variation [38].

Derivation of the procedure for calculation of the maximum allowable RAP content is as follows. ASTM D 4460 gives equations for calculating standard deviation values for quantities determined from calculations involving two other values. From these equations, the following formula for calculating the standard deviation of a blend of two materials can be derived:

$$
\sigma_{m}=\sqrt{\alpha^{2} \sigma_{a}^{2}+(1-\alpha)^{2} \sigma_{b}^{2}+\left(\bar{X}_{a}^{2}+\bar{X}_{b}^{2}\right) \sigma_{\alpha}^{2}}
$$

where $\sigma_{m}$ —standard deviation of the mixture; $\sigma_{a}$ —standard deviation of component "a"; $\sigma_{b}$ —standard deviation of component " $b$ "; $\alpha$-proportion of component "a" in the mixture; $\bar{X}_{a}^{2}$ - mean value for component "a"; $\bar{X}_{b}^{2}$-mean value for component " $\mathrm{b}$ "; and, $\sigma_{\alpha}$-standard deviation of the proportions.

We can rewrite this for percent passing for a selected sieve for HMA mixtures consisting of a blend of new HMA materials with RAP [48]:

$$
\sigma_{P M}=\sqrt{w_{R}^{2} \sigma_{P R}^{2}+w_{N}^{2} \sigma_{P N}^{2}+\left(\bar{P}_{R}^{2}+\bar{P}_{N}^{2}\right) \sigma_{W}^{2}}
$$

where $\sigma_{P M}$-standard deviation of percent passing for a selected sieve for the mixture with RAP (i.e., RHMA); $w_{R}$-weight fraction of RAP in the mixture; $\sigma_{P R}$-standard deviation of percent passing for the selected sieve for the RAP; $w_{N}$-weight fraction of new materials (new HMA) in the mixture $=\left(1-w_{R}\right) ; \sigma_{P N}$-standard deviation of percent passing for the selected sieve for the new HMA; $\bar{P}_{R}$-mean value for RAP\% passing for the selected sieve; $\bar{P}_{N}$-mean value for new HMA $\%$ passing for the selected sieve; and, $\sigma_{w}$-standard deviation of the weight fractions, also called "batching variability".

Equation (3) can be solved for the maximum amount of RAP that can be added to new material without increasing the standard deviation for percent passing on the selected sieve above a selected maximum value by application of the quadratic equation:

$$
\operatorname{Max} \cdot R A P \%=\frac{-b+\sqrt{b^{2}-4 a c}}{2 a} 100 \%,
$$


where Max.RAP\%—maximum amount of RAP that can be added to the mix, weight \%; $a=\sigma_{P R}^{2}+\sigma_{P N}^{2}$; $b=-2 \sigma_{P N}^{2} ; c=\sigma_{P N}^{2}+\left(\overline{P_{P N}^{2}}+P_{N}^{2}\right) \sigma_{w}^{2}-\sigma_{P M / M a x}^{2} ;$ and, $\sigma_{P M / M a x}^{2}$ is the maximum allowable standard deviation for percent passing for the selected sieve.

Because asphalt is temperature sensitive, good preheating of RAP is helpful to eliminate the agglomerates of RAP to promote the dispersion of RAP during the hot recycling process [49]. When applying the first heat transfer method, superheating temperature of virgin mineral materials (aggregate) is calculated according to the following empirical formula applied in practice [50]:

$$
T_{\text {v.a. }}=\frac{T_{R H M A}-S \cdot T_{R A P}}{1-S}+\frac{4 \cdot S \cdot W_{R A P}}{1-S}\left(637-T_{R A P}\right),
$$

where $T_{\text {v.a. }}$ - superheating temperature of virgin mineral materials (aggregates), ${ }^{\circ} \mathrm{C} ; T_{R H M A}$-required temperature of recycled hot mix asphalt, which depends on the grade of the bitumen binder, ${ }^{\circ} \mathrm{C}$; $S$-ratio of RAP batching mass in the recycled hot mix asphalt mixture, in units; $T_{R A P}$-temperature of $\mathrm{RAP},{ }^{\circ} \mathrm{C}$; and, $W_{R A P}-$ moisture (water content) of RAP, in units.

This formula (1) contains four variables, two of which $\left(T_{R H M A}, S\right)$ show the temperature of RAP and component composition, whereas other two $\left(T_{R A P}, W_{R A P}\right)$ - show RAP temperature and moisture. Experimental investigations showed that RAP may absorb from 0.7 to $6.5 \%$ of moisture. The average made up $3.40 \%$. Therefore, it is recommended to store it in warehouses. It is likely that not all humidity is removed from RAP in a parallel drum. The quantity and temperature of a batched.

RAP, which depends on its transfer type impacted by the production technology of RHMA in $\mathrm{AMP}$, allows to calculate the temperature at which virgin aggregates shall be heated. According to formula (6), it was identified how the temperature required for heating virgin aggregates varies when the moisture of RAP varies from 0 to $8 \%$, and its quantity in RHMA varies from 5 to $50 \%$ (Figure 4). When making calculations, it was assumed that the initial temperature of RAP is equal to ambient temperature of $15^{\circ} \mathrm{C}$ (Figure 4a). RAP was heated in a parallel drum to the working temperature of $100^{\circ} \mathrm{C}$ (Figure $4 \mathrm{~b}$ ), and it also contained some residual temperature.

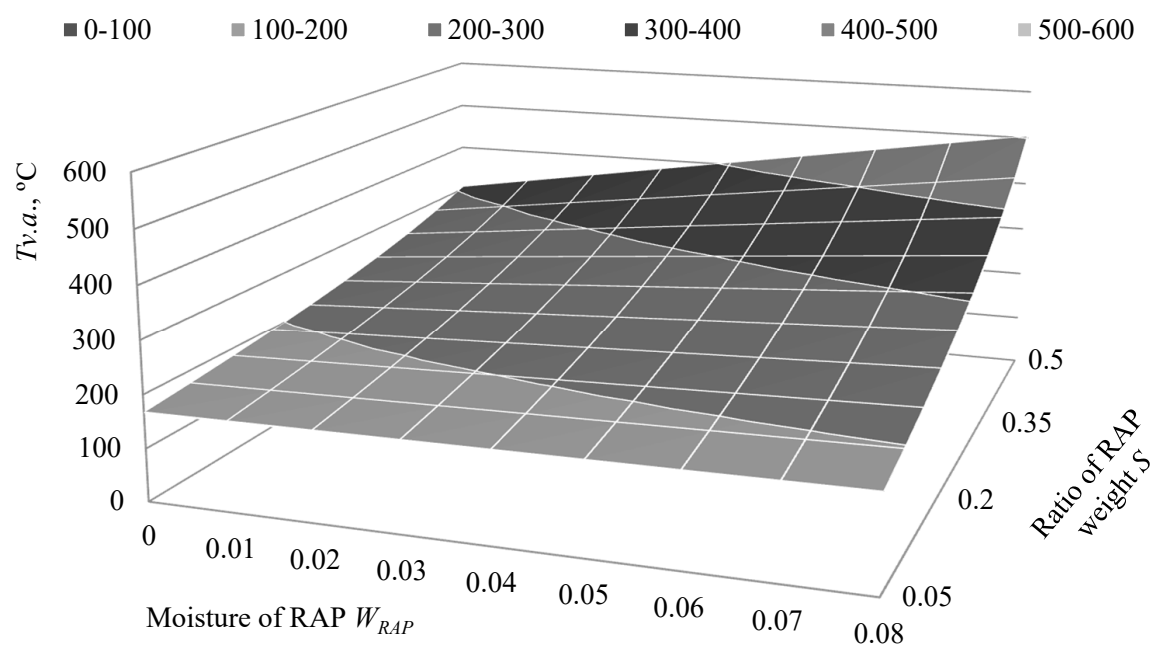

(a)

Figure 4. Cont. 


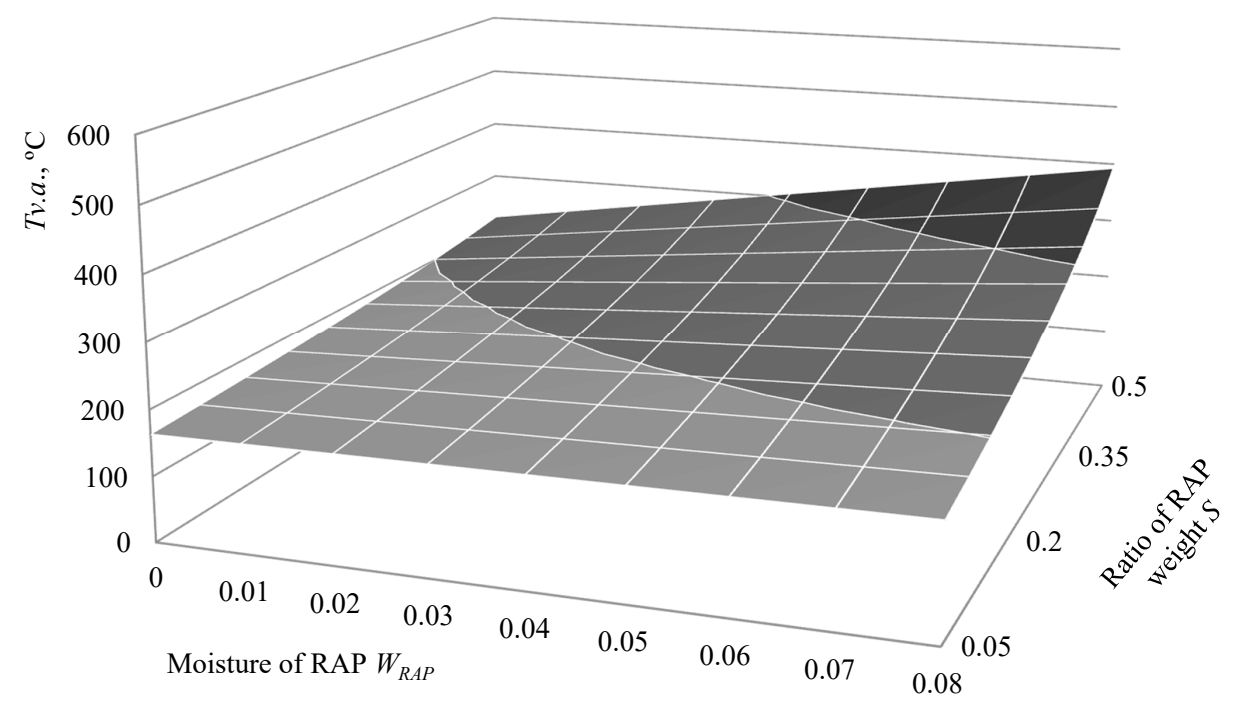

(b)

Figure 4. Dependence of superheating temperature of virgin mineral materials on the ratio of RAP weight and moisture of RAP when $T_{R A P}$ is as follows: (a) $-15^{\circ} \mathrm{C} ;(\mathbf{b})-100{ }^{\circ} \mathrm{C}$.

It was estimated that if RAP content in RHMA mixture is $50 \%$ and RAP moisture is $2 \%$, then the temperature required to heat virgin aggregates when producing $160^{\circ} \mathrm{C}$ RHMA with RAP heated in a parallel drum is $262{ }^{\circ} \mathrm{C}$, and with non-heated RAP-even $354^{\circ} \mathrm{C}$. The difference made up $92{ }^{\circ} \mathrm{C}$.

\section{RAP Batching Accuracy and Precision}

RHMA mixture of different RAP content was produced in one asphalt producing company in a batch-type asphalt mixing plant (AMP), Ammann Euro A 240, the highest capability of which was $Q_{\max }=240 \mathrm{t} / \mathrm{h}$, and the highest mass of one mix batch was $3000 \mathrm{~kg}$. RAP feeding, transporting, drying, and heating, as well as batching devices were mounted in addition (Figure 5).

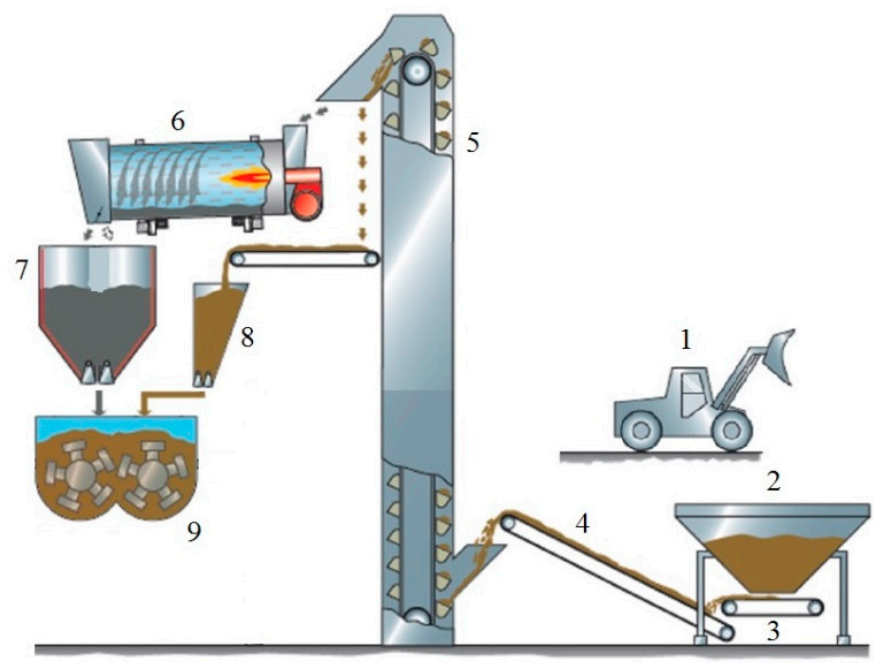

Figure 5. The technological scheme of RAP hot and cold recycling in batch AMP: 1 -wheel loader; 2-RAP feeder; 3-belt scale; 4-collecting conveyor; 5-RAP elevator; 6-parallel drum; 7-recycling buffer silo with weighing appliance and recycling scale; 8 - cold recycling addition via buffer silo and belt scale; 9-mixer. 


\subsection{Methods}

The following mixture for a road pavement surface and base courses of two types was produced in a batchAMP with preheated RAP: with $25 \%$ and $50 \%$ of RAP, AC 16 PD and AC 22 PS, respectively. The grade of AC 16 DP according to the national standard TRA ASFALTAS 09 is asphalt concrete (AC); maximum size of particles-16mm; purpose-for pavement single ply surface course (PD). The grade of AC $22 \mathrm{PS}$ is also asphalt concrete (AC); maximum size of particles-22 $\mathrm{mm}$; purpose-for pavement base course (P); also, purpose-for the heavy load (S). To investigate the accuracy and precision of RAP batching, technological data about RHMA mixtures produced in 2014, which were stored in an APM handling computer, were used. AMP handling software presents rated (target) and factual data on the name and number of job-mix formula (JMF), weight, mixing time, and temperature of each RHMA mix batch. Masses of all mineral materials, bitumen, additives, and RAP weighed batches are presented as well.

For statistical purposes, only the data when most of RHMA mixture was produced were used: 10-day AC 16 PD mixture production data and 12-day AC 22 PS grade hot-mix asphalt (HMA) mixture production data. Quite large sample sizes, presented in Table 1, allowed the study to obtain rather dependable investigation data. RHMA mix batches of less than $2800 \mathrm{~kg}$ (outliers) were eliminated from each sample size. Statistical investigation was conducted on the data of $3041 \mathrm{mix}$ batches, for the production of which approximately $3400 \mathrm{t}$ of RAP was used and approximately $9000 \mathrm{t}$ of RHMA mixture were produced.

Table 1. Sample sizes of the data used in the investigation

\begin{tabular}{cccc}
\hline Type of RHMA & Days & Total Sample Size & Sample Size Without Outliers \\
\hline AC 16 PD & 10 & 1424 & 1324 \\
AC 22 PS & 12 & 1617 & 1569 \\
\hline
\end{tabular}

Statistical data were calculated through the use of Statgraphics Centurion XVII software package (Statpoint Technologies, Inc., Warrenton, VA, USA) for statistical processing, which allowed to identify the accuracy and precision of RAP batching in a batch-type AMP. AMP handling computer data of each working day's lot were grouped and classified by days and grades of RHMA mixture. Total weight $Q_{\text {batch } i}$ of RHMA mix batch and weighed RAP batch mass $q_{R A P i}$ were calculated. RAP percentage content in each asphalt mix batch was calculated according to this data:

$$
x_{R A P i}=\frac{q_{R A P i}}{Q_{\text {batchi }}} \times 100
$$

where $x_{R A P i}-$ RAP content in $i$ RHMA mix batch, $\%$; $q_{R A P i}-$ RAP batch mass, $\mathrm{kg}, Q_{\text {batch }}$-RHMA mix batch mass, $\mathrm{kg} ; i-i$ RHMA mix batch $(i=1,2, \ldots N, N-$ RHMA mix batches' number).

Statistical indices of the produced RHMA mixture of both grades RAP batch mass position and variation were calculated, and diagrams and histograms were drawn (Figures 6 and 7).

The accuracy of RAP batching was identified by comparing average RAP content deviation from JMF in the produced RHMA mixture:

$$
\Delta q_{R A P}=\frac{\bar{q}_{R A P}-q_{R A P, J M F}}{q_{R A P, J M F}} \times 100,
$$

where $\bar{q}_{R A P}$-average of RAP batches mass, $\mathrm{kg} ; q_{R A P, J M F}$ - target RAP batch mass according to JMF, $\mathrm{kg}$.

Standard deviation was used to evaluate the precision of RAP batching (Figure 7).

Normal distribution of both sample sizes of RAP batch mass was tested, which enabled the calculation of the average precision of RAP batching process. Normal distribution of experimental data was investigated by applying skewness and kurtosis. The values of the coefficient of skewness $s k$ 
and coefficient of kurtosis $k u$ calculated from data of sample size were compared with their respective standard deviations $s_{s k}$ and $s_{k u}$ :

$$
\begin{gathered}
s_{s k}=\sqrt{\frac{6 n(n-1)}{(n-2)(n+1)(n+3)}}, \\
s_{k u}=\sqrt{\frac{24 n(n-1)^{2}}{(n-3)(n-2)(n+3)(n+5)}},
\end{gathered}
$$

where $n$-the sample size (number of measurements). When $|s k|<3 s_{s k}$ and $|k u|<5 s_{k u}$, it can be considered that the normality hypothesis of empirical data is accepted. Otherwise, the raised hypothesis is rejected or accepted as doubtful.

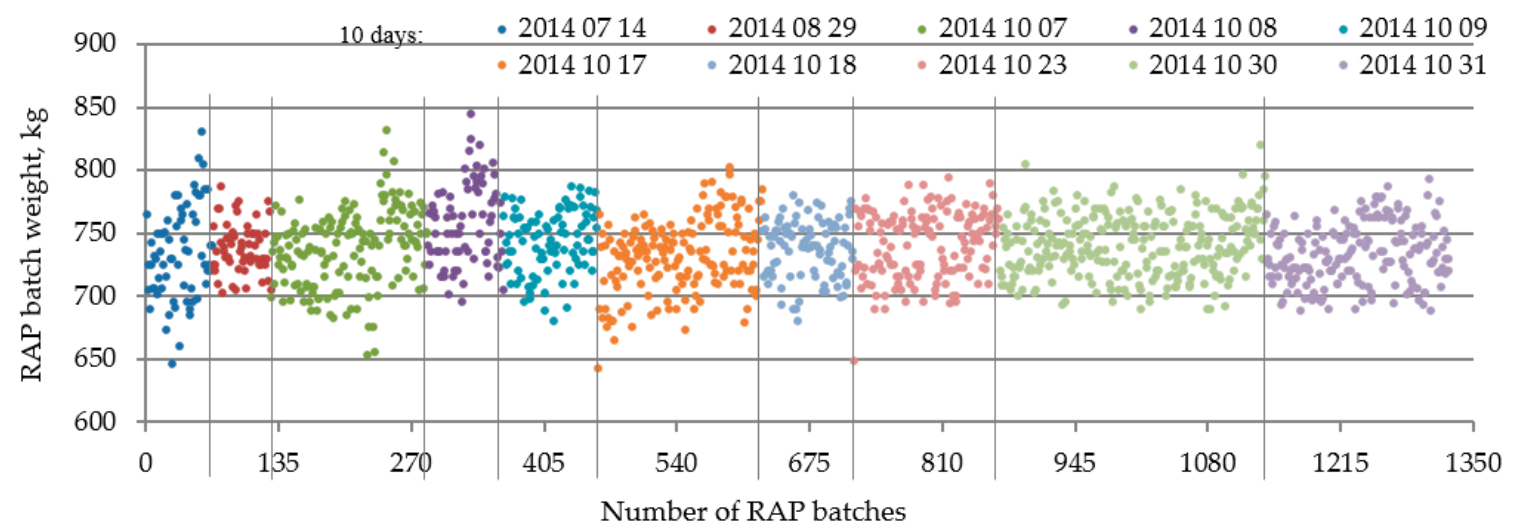

(a)

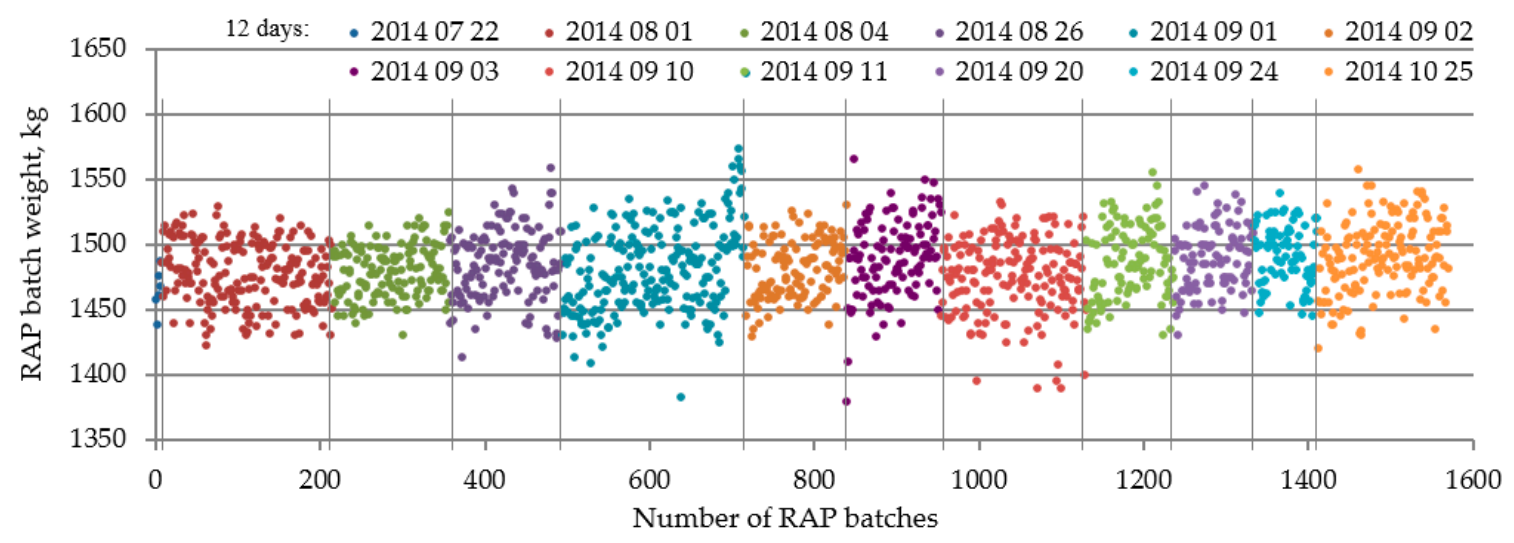

(b)

Figure 6. Distribution of RAP separate batch masses. When its job mix formula (JMF) is as follows: (a) $-750 \mathrm{~kg}$; (b) - $1500 \mathrm{~kg}$.

\subsection{Materials}

RHMA mixtures were produced according to various JMF's. To produce AC 16 PD grade mixture, imported fillers (IF), crushed gravel sifting, reclaimed dust (RD), natural sand, various fraction crushed gravel, and 100/150 grade road bitumen were used. AC 22 PS grade RHMA mixture was produced from $0 / 2 \mathrm{~mm}$ and $0 / 5 \mathrm{~mm}$ fraction natural sand, $5 / 8 \mathrm{~mm}, 8 / 11 \mathrm{~mm}$ and $11 / 22 \mathrm{~mm}$ fraction gravel, and 50/70 grade road bitumen. Additives were not used for RHMA mixture production. The batch masses of all materials' finite batching in one recycled HMA mix batch, the mass of which according to JMF is $3000 \mathrm{~kg}$, are presented in Table 2. 


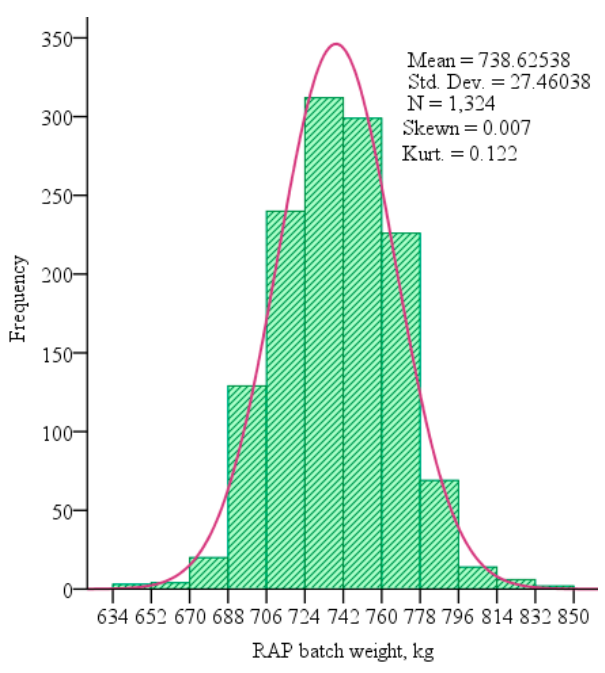

(a)

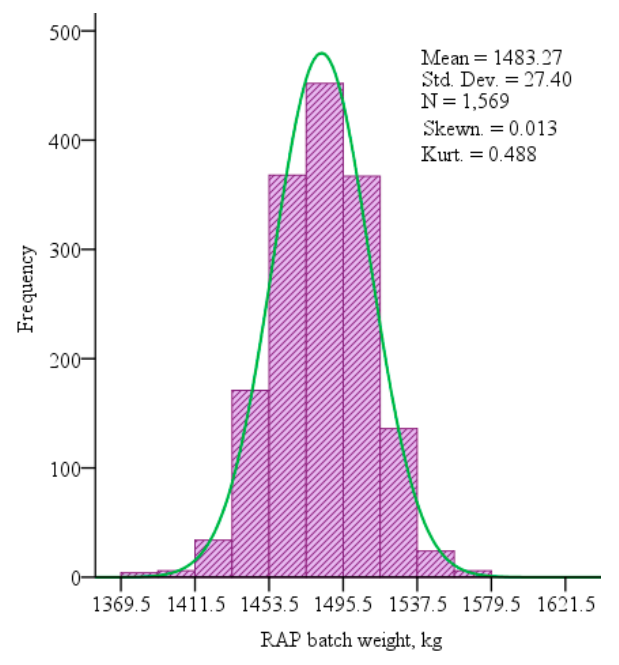

(b)

Figure 7. Distribution histograms, theoretical curves of normal distribution and statistical parameters of RAP batch masses in HMA batches of mixtures: (a)—AC 16 PD (750 kg); (b) - AC 22 PS (1500 kg).

Table 2. RAP composition, $\%$.

\begin{tabular}{ccccccc}
\hline \multirow{2}{*}{ Particle Size, $\mathbf{~ m m}$} & \multicolumn{7}{c}{ Subsample Number } & \multirow{2}{*}{ Average } \\
\cline { 2 - 6 } & I & II & III & IV & V & \\
\hline$>11.2$ & 6.3 & 7.5 & 8.4 & 8.7 & 7.5 & 7.7 \\
$>2$ & 69.4 & 73.4 & 71.2 & 68.5 & 68.7 & 70.6 \\
$0.063-2$ & 30.4 & 26.5 & 28.6 & 31.3 & 31.2 & 29.2 \\
$<0.125$ & 0.5 & 0.3 & 0.2 & 0.3 & 0.3 & 0.3 \\
$<0.063$ & 0.2 & 0.1 & 0.2 & 0.2 & 0.1 & 0.2 \\
Bitumen & 4.78 & 4.73 & 4.86 & 4.81 & 4.43 & 4.72 \\
\hline
\end{tabular}

To produce RHMA mixture, crushed and sieved RAP, the size of which was not larger than $32 \mathrm{~mm}$, were used. RAP was prepared according to the third principle and technological scheme (Figure 3). When designing the composition of RHMA mixture and determining JMF, RAP grading and hot fraction were evaluated. Several sample units were taken from the adjacent places of the sheltered stock of RAP and prepared for use. The material of several sample units was put into a subsample. In total, five subsamples were taken this way, each of which was tested separately in a laboratory. RAP investigation data are presented in Table 3.

Table 3. RHMA mixture batch composition according to JMF (finite batching materials' batch mass in $\mathrm{kg}$ in one RHMA mix batch of $3000 \mathrm{~kg}$ ).

\begin{tabular}{cllllllllll}
\hline \multirow{2}{*}{ RHMA Mixture Group } & \multirow{2}{*}{ RAP } & \multirow{2}{*}{ IF } & \multirow{2}{*}{ RD } & \multicolumn{6}{c}{ Hot Aggregate Fractions, mm } & \multirow{2}{*}{ Virgin Bitumen } \\
\cline { 6 - 10 } & & & & $\mathbf{0 / 2}$ & $\mathbf{2 / 5}$ & $\mathbf{5 / 8}$ & $\mathbf{8 / 1 1}$ & $\mathbf{1 1 / 1 6}$ & $\mathbf{1 1 / 3 2}$ & \\
\hline AC 16 PD & 750 & 99 & 99 & 612 & 219 & 411 & 384 & 306 & - & 120 \\
AC 22 PS & 1500 & - & - & 141 & 87 & 297 & 144 & - & 780 & 51 \\
\hline
\end{tabular}

The mean of five subsamples was taken as RAP average composition. RAP homogeneity was estimated by standard deviation. 


\section{Results and Discussion}

The aim of the study was to identify how accurately and precisely RAP is batched when producing an asphalt mixture. The experiment data show that when producing RHMA mixture AC 16 PD (with 25\% RAP) for pavement single ply surface course, the batched quantity of RAP into an AMP mixer was on average $\bar{q}_{R A P}=738.63 \mathrm{~kg}$. According to Equation (8), batching accuracy $\Delta q_{R A P}=\frac{738.63-750}{750} \times 100=-1.52 \%$. RAP batch mass varied from $643 \mathrm{~kg}$ to $845 \mathrm{~kg}$. Range $R=q_{\max }-q_{\min }=202 \mathrm{~kg}$ (Figure 6a). Standard deviation showing batch mass variation was $s_{q_{R A P}}=27.46 \mathrm{~kg}$ and coefficient of variation was $V_{q}=3.72 \%$. The specifications do not regulate AMP batching tolerances of bitumen, hot and cold mineral materials. They are specified in ASTM Standard Specification for mixing plants for hot-mixed, hot-laid bituminous paving mixture. According to the Specifications above, the automatic proportioning system shall be capable of consistently delivering materials within the full range of a batch size of the following tolerances (Table 4).

Table 4. Tolerances of batch masses of AMP batchers' materials according to ASTM D 995-95b.

\begin{tabular}{cc}
\hline Materials & Total Batch Mass of a Paving Mix, \% \\
\hline Batch aggregate component & \pm 1.5 \\
Mineral filler & \pm 0.5 \\
Bituminous material & \pm 0.1 \\
Zero return (aggregate) & \pm 0.5 \\
Zero return (bituminous material) & \pm 0.1 \\
\hline
\end{tabular}

The electric circuits for the above delivery tolerances of each cut-off interlock shall be capable of providing the total span for the full allowable tolerance for maximum batch size. Tolerance controls shall be automatically or manually adjustable to provide spans that are suitable for less than full-size batches. The automatic controls and interlock cut-off circuits shall be capable of being consistently coordinated with the batching scale or meter within an accuracy of $0.2 \%$ of the nominal capacity of the said scale or meter throughout the full range of the batch sizes according to ASTM D995-95b.

Having investigated all 1569 asphalt mix batches of grade AC 22 PS RHMA mixture (with 50\% RAP content) produced in 12 days for the base course, it was identified that RAP is batched rather accurately. When the mean of RAP of all the batches is $\bar{q}_{R A P}=1483.27 \mathrm{~kg}$, and $q_{R A P, J M F}=1500 \mathrm{~kg}$, then according to the mean RAP is batched rather accurately: $\Delta q_{R A P}=\frac{1483.27-1500}{1500} \times 100=-1.11 \%$ and error is less than $1.5 \%$, i.e., lower than tolerances. The value of batching preciseness is standard deviation $s_{q_{R A P}}=27.40 \mathrm{~kg}$, and variation coefficient $V_{q}=1.85 \%$. The maximum mass of a RAP batch is $1631 \mathrm{~kg}$ and the minimum mass is $1380 \mathrm{~kg}$. Range $R=q_{\max }-q_{\min }=251 \mathrm{~kg}$ (Figure 6b).

Taking into consideration the specification that not only RAP batch mass mean is $\bar{q}_{R A P}$, but its weighed batch mass $q_{R A P}$ differed from rated value $q_{R A P, J M F}$ does not exceed the permitted tolerances $( \pm 1.5 \%)$, when $q_{R A P, J M F}=750 \mathrm{~kg}$, the amount of weighed RAP shall be not less than $738.75 \mathrm{~kg}$ and not more than $761.25 \mathrm{~kg}$. When $q_{R A P, J M F}=1500 \mathrm{~kg}$, the minimum permitted batch mass of RAP may be $1477.5 \mathrm{~kg}$, and the maximum batch mass $1522.5 \mathrm{~kg}$. In fact, the diagrams (Figure 7) above show that the mass of quite a lot of RAP separate batches does not meet tolerance specifications. Only $29 \%$ of them (392 out of 1324) are within the range of permitted tolerances, when the estimated $q_{R A P, J M F}=750 \mathrm{~kg}$ and $51 \%$ (803 out of 1569) when it was $q_{R A P, J M F}=1500 \mathrm{~kg}$.

The normality of data distribution was verified according to skewness and kurtosis. Empirical coefficient of skewness of RAP batch masses $s k$ were 0.007 and 0.013 , and the coefficient of kurtosis $k u$ were 0.122 and 0.488 , respectively (Figure 7). They were compared to the critical values which depend only on sample size $n$. When RAP batch sample sizes $n$ were 1324 and 1569 , standard deviations of skewness and kurtosis were calculated as follows: $s_{s k}=0.067, s_{s k}=0.062$ and $s_{k u}=0.134, s_{k u}=0.123$ (AC 16PD and AC 22PS mixtures, respectively). The estimated $s_{s k}$ values were multiplied by 3 , which resulted in $3 s_{s k}=0.202$ and $3 s_{s k}=0.185$, respectively. Standard deviation of kurtosis $s_{k u}$ was multiplied by 5 , which resulted in $5 s_{k u}=0.672$ and $5 s_{k u}=0.617$, respectively. 
When $|s k|<3 s_{s k}$ and $|k u|<5 s_{k u}$, it could be stated that the hypothesis of normality of the empirical data is confirmed. The normality of sample size data distribution can be verified using more complex methods, such as Kolmogorov and Pearson. Null hypothesis can be verified according to the Bartlett criterion, where the available data is close to normal distribution.

Thus, Bartlett's criterion was used to compare the variances of various sample sizes according to normal distribution. This criterion is convenient to compare two or more variances of the normal distribution sample sizes when these sample sizes are unequal. If statistics $B$ is less than $\chi_{\alpha, v}^{2}$, RAP batch mass variation is statistically equal. Therefore, the average calculated value of sample variance $s_{q}^{-2}=752.52 \mathrm{~kg}$ and general standard deviation $\bar{s}_{q}=27.43 \mathrm{~kg}$. Statistics $B=0.0094$ is less than critical $\chi_{\alpha, v}^{2}=3.84$ with the selected $\alpha=0.05$ significance level and degrees of freedom $v=l-1$ (where $l$-the number of comparable variances (samples). Therefore, it could be concluded that both (with $25 \%$ and $50 \%$ RAP content) batch mass variation (standard deviation $s_{q}=27.46 \mathrm{~kg}$ and $s_{q}=27.40 \mathrm{~kg}$ ) are statistically equal.

The physical and mechanical properties of a recycled HMA mixture are influenced by RAP percentage content in each mix batch of RHMA mixture. This parameter allows to determine the proportion of RAP in the whole mix batch. When hot fractions, IF and RD batches are weighed in AMP, their mass like that of RAP has a certain variation, which influences the variation of RHMA mixture batch masses (Figure 8). Therefore, the mass of RHMA mixture batches always differs from JMF, i.e., from $3000 \mathrm{~kg}$ and is of stochastic type.

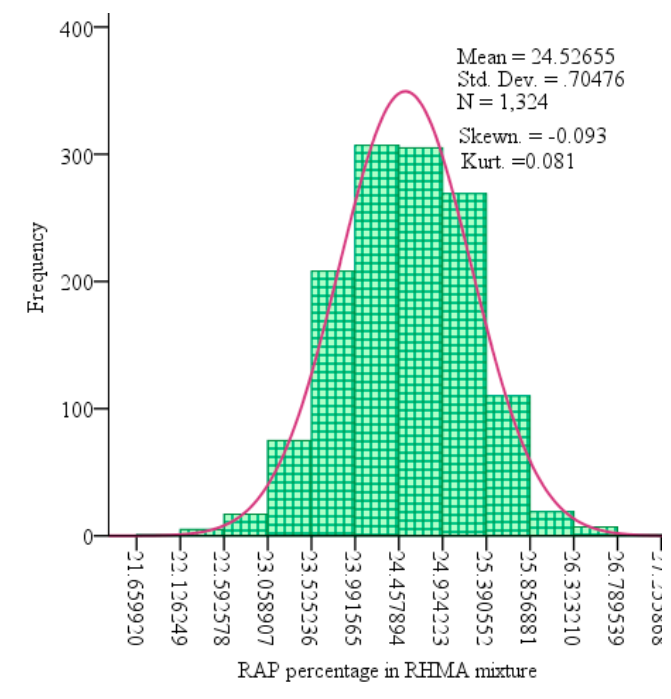

(a)

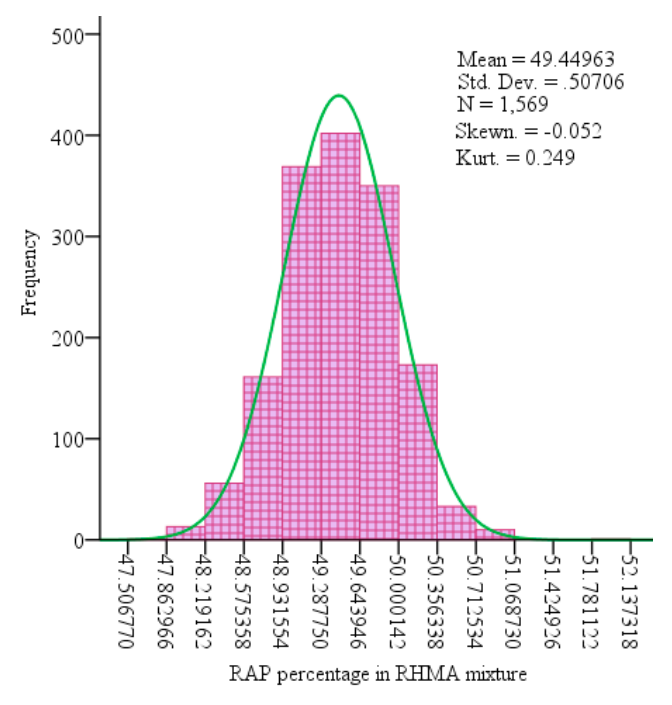

(b)

Figure 8. Normal distribution curves and statistical indices of histogram of RAP percentage content in recycled hot mix asphalt (RHMA) mixture, when its content according to JMF had to be: (a) - $25 \%$; (b) $-50 \%$.

Average values $\bar{x}_{R A P}$ of RAP percentage Equation (7) of both sample sizes out of 1324 (with 25\% RAP) and 1569 (with 50\% RAP) were approximate to JMF (Figure 8). $\bar{x}_{R A P_{25}}=24.53 \%$, $\bar{x}_{R A P_{50}}=49.45 \%$. Standard deviation $s_{x}$ of RAP percentage content was rather low: in mix batches with $25 \%$ of RAP content $-0.705 \%$; in mix batches with $50 \%$ of RAP content $-0.507 \%$, and their variation coefficients were $v c_{x 25}=2.87 \%$ and $v c_{x 50}=1.03 \%$, respectively.

Average values $\bar{x}_{R A P}$ of RAP percentage content Equation (7) of both sample sizes out of 1324 (with RAP percentage content in RHMA mix batches were approximate to those designed in JMF; however, histograms show that most of the data is grouped below the value of JMF (Figure 8). There was a tendency of lack of RAP content in RHMA mixture. 
When asphalt pavement is hot-mix in-plant recycled, the sequence of technological operations depends on the structure of an AMP and additional equipment for feeding, transporting, and proportioning or batching of RAP. The model constructed by the authors contains two types of technological operations. First, hot-mix recycling in a batch plant, when RAP is dried and heated up due to the contact with superheated virgin mineral materials, i.e., conductive heat transfer occurs. Second, when RAP is dried and heated up in an additional parallel dryer, i.e., convective heat transfer occurs. These two recycling technologies are popular in the European Union countries. The model also contains hot-mix recycling in drum-mix and double-barrel plant technologies, when RAP dry out and heat up due to the heat exchange between them and superheated virgin mineral materials: conductive heat transfer occurs. These technologies are more popular in the USA.

When up to $10 \%$ or $20 \%$ of RAP is used, such aged asphalt pavement material may be supplied to four batch AMP places: the bottom part of a bucket hot elevator with aggregate, hot fractions' unsieved mineral materials bypass hot bin, hot mineral material fractions batcher's weight hopper, forced mixing two-shaft mixer. Such four RAP feeding places into AMP, which were selected in advance, have both advantages and disadvantages.

The aim is to consume less heat energy (gas or liquid fuel), required to remove water content in RAP and to reduce the pollution of ambient air. Ready-to-use RAP is stored in a closed warehouse, which protects the material from precipitation water. When the conductive heat transfer method is applied to vaporize the water content in RAP and to reduce the viscosity of aged bitumen, the superheated temperature of virgin mineral materials mostly depends on RAP moisture (water content) and its percentage in RHMA. When the value of these parameters increases, the required temperature of heating and drying of virgin aggregates in a drum increases, which is calculated according to the presented empirical formula.

The composition of HMA mixture with less than $100 \%$ of RAP developed in a laboratory as accurately and precisely as possible shall be guaranteed when producing it in an AMP. Inevitable systematic and random errors of batching RAP increase the deviations of RHMA mixture component content from JMF and their variation. The size of errors depends on AMP structure, technical condition, RAP percentage in RHMA and AMP operator's actions when setting the technological parameters of the recycling process and handling them.

\section{Conclusions}

The application of these twelve road asphalt pavement hot recycling principles allows us to expect the best possible properties and pavement of the course with reclaimed asphalt pavement. These principles may be used for asphalt pavement hot-in-place surface recycling and hot-mix in-plant recycling.

According to JMF, RAP content was $25 \%$ (750 kg batch mass, 10 days, $n=1324$ batches) and during the investigation, it was 50\% (1500 kg batch mass, 12 days, $n=1569$ batches). The mean of $738.6 \mathrm{~kg}$ of all the AMP batches with its required content of $25 \%$ mass was less than $750 \mathrm{~kg}$, i.e., by $1.52 \%$, and with the required RAP content of $50 \%$, the mean of $1483.3 \mathrm{~kg}$ was less than $1500 \mathrm{~kg}$, i.e., by $1.1 \%$. The accuracy of RAP batching are almost met or completely met the tolerances of the mean specified in ASTM D995-95b on the batch aggregate component $( \pm 1.5 \%)$ content. Due to the high variation of the batch mass of separate RAP, the tolerance of $\pm 1.5 \%$ was met only by $29.6 \%$ and $51.5 \%$, respectively, of all RAP batches. The accuracy and compliance of batch masses with tolerances increases when a higher percentage of RAP is batched.

The standard deviation mean calculated according to two standard deviations $\left(s_{q}=27.46 \mathrm{~kg}\right.$ and $s_{q}=27.40 \mathrm{~kg}$ ) was $27.4 \mathrm{~kg}$. The variation coefficient of RAP batch mass was $3.72 \%$ (when RAP batch mass according to JMF was $750 \mathrm{~kg}$ ) and approximately two times less $(1.85 \%)$, when according to JMF RAP batch mass was $1500 \mathrm{~kg}$.

RAP batch mass deviations from JMF and their variation influence RAP percentage content in a recycled HMA mixture. When the mass of an asphalt mix batch inevitably varies, the variation of 
RAP percentage in RHMA mixture increases even more. When RAP content according to JMF was $25 \%$ in RHMA, the mean of its percentage content was $24.53 \%$, and when according to JMF it was $50 \%$, in fact, it was $49.45 \%$. In both cases, RAP percentage content in RHMA mixture varies according to normal distribution. Standard deviations of RAP percentage content in RHMA mixture were $0.705 \%$ and $0.507 \%$, and statistically did not diverge.

Acknowledgments: The authors would like to acknowledge Fegda JSC for providing part of materials and laboratory equipment required for the research work.

Author Contributions: Henrikas Sivilevičius systematized hot regeneration principles, submitted the model of asphalt pavement recycling operations (Figure 3) and wrote the introduction. Justas Bražiūnas conceived and designed the experiments, wrote and edited the paper. Olegas Prenkovskis processed and analyzed the data. All authors read and approved the final manuscript.

Conflicts of Interest: The authors declare no conflict of interest.

\section{References}

1. Tran, N.H.; Taylor, A.; Willis, R. Effect of Rejuvenator on Performance Properties of HMA Mixtures with High RAP and RAS Contents; Report Number 12-05; National Center for Asphalt Technology: Auburn, AL, USA, 2012.

2. Zaumanis, M.; Mallick, R.B. Review of very high-content reclaimed asphalt use in plant-produced pavement: State of the art. Int. J. Pavement Eng. 2015, 16, 39-55. [CrossRef]

3. Solaimanian, M.; Savory, E. Variability Analysis of Hot-Mix Asphalt Concrete Containing High Percentage of Reclaimed Asphalt Pavement. Transp. Res. Rec. 1996, 1543, 89-96. [CrossRef]

4. Howard, I.L.; Cooley, L.A., Jr.; Doyle, J.D. Laboratory Testing and Economic Analysis of High RAP Warm Mixed Asphalt; Mississippi Department of Transportation: Jackson, MS, USA, 2009.

5. Bloomquist, D.; Diamond, G.; Oden, M.; Ruth, B.; Tia, M. Engineering and Environmental Aspects of Recycled Materials for Highway Construction; Western Research Institute: Laramie, WY, USA, 1993.

6. Apeagyei, A.K.; Clark, T.M.; Rorrer, T.M. Stiffnes of high-RAP asphalt mixtures: Virginia's experience. J. Mater. Civ. Eng. 2013, 25, 747-754. [CrossRef]

7. Rad, F.Y.; Sefidmazgi, N.R.; Bahia, H. Application of diffusion mechanism. Degree of Blending between fresh and recycled asphalt pavement binder in dynamic shear rheometer. Transp. Res. Rec. J. Transp. Res. Board. 2014, 2444, 71-77. [CrossRef]

8. Miró, R.; Valdés, G.; Martínez, A.; Segura, P.; Rodriguez, C. Evaluation of high modulus mixture behaviour with high reclaimed asphalt pavement (RAP) percentages for sustainable road construction. Const. Build. Mater. 2011, 25, 3854-3862. [CrossRef]

9. Mogawer, W.; Bennert, T.; Daniel, J.S.; Bonaquist, R.; Austerman, A.; Booshehrian, A. Performance characteristics of plant produced high RAP mixtures. Road Mater. Pavement Des. 2012, 13, 183-208. [CrossRef]

10. Bražiūnas, J.; Sivilevičius, H. The bitumen batching system's modernization and its effective at the asphalt mixing plant. Transport 2010, 25, 325-335. [CrossRef]

11. Zaumanis, M.; Mallick, R.B.; Frank, R. $100 \%$ recycled hot mix asphalt: A review and analysis. Resour. Conserv. Recycl. 2014, 92, 230-245. [CrossRef]

12. Santos, L.G.D.P.; Baptista, A.M.D.C.; Capitão, S.D. Assessment of the Use of Hot-Mix Recycled Asphalt Concrete in Plant. J. Transp. Eng. 2010, 136, 1159-1164. [CrossRef]

13. Estakhri, C.; Spiegelman, C.; Gajewski, B.; Yang, G.; Little, D. Recycled Hot-Mix Asphalt Concrete in Florida: A Variability Study; International Center for Aggregates Research: Austin, TX, USA, 1999.

14. West, R.; Willis, J.R.; Marasteanu, M. Improved Mix Design, Evaluation, and Materials Management Practices for Hot Mix Asphalt with High Reclaimed Asphalt Pavement Content; NCHRP Report 752; NCHRP: Washington, DC, USA, 2013.

15. National Center for Asphalt Technology (NCAT). LTPP Data Shows RAP Mixes Perform as Well as Virgin Mixes. In Asphalt Technology News; NCAT: Auburn, AL, USA, 2009; Volume 21.

16. Diefenderfer, S.; Nair, H. Evaluation of Production, Construction, and Properties of High Reclaimed Asphalt Pavement Mixture. Transp. Res. Rec. J. Transp. Res. Board. 2014, 2445, 75-82. [CrossRef]

17. Bonaquist, R. Can I run more RAP? HMAT Hot Mix Asph. Technol. 2007, 12, 11-13. 
18. Mohammad, L.; Wu, Z.; Zhang, C.; Khattak, M.; Abadie, C. Variability of Air Voids and Mechanistic Properties of Plant-Produced Asphalt Mixtures. Transp. Res. Rec. J. Transp. Res. Board. 2004, 1891, 85-97. [CrossRef]

19. Ali, H.; Grzybowski, K. Life cycle of hot in-place pavement recycling. Case study. Transp. Res. Rec. J. Transp. Res. Board. 2012, 2292, 29-35. [CrossRef]

20. Tahmoorian, F.; Samali, B.; Tam, V.W.Y.; Yeaman, J. Evaluation of mechanical properties of recycled material for utilization in the asphalt mixtures. Appl. Sci. 2017, 7, 763. [CrossRef]

21. Kriz, P.; Grant, D.L.; Veloza, B.A.; Gale, M.J.; Blahey, A.G.; Brownie, J.H.; Shirts, R.D. Blending and diffusion of reclaimed asphalt pavement and virgin asphalt binders. Road Mater. Pavement Des. 2014, 15, 78-112. [CrossRef]

22. Le Guen, L.; Huchet, F.; Tamagny, P. Drying and heating modelling of granular flow: Application to the mix-asphalt process. J. Appl. Fluid Mech. 2011, 4, 71-80.

23. Peinado, D.; de Vega, M.; Garcia-Hernando, N.; Marugan-Cruz, C. Energy and exergy analysis in an asphalt's rotary dryer. Appl. Therm. Eng. 2011, 31, 1039-1049. [CrossRef]

24. Wang, H.; Hao, P.; Xue, L. Laboratory evaluation of microwave heating method for hot in-place recycling. J. Test. Eval. 2011, 39, 1070-1077.

25. Carpenter, S.H.; Wolosick, J.R. Modifier influence in the characterization of hot-mix recycled material. Transp. Res. Rec. J. Transp. Res. Board. 1980, 777, 15-22.

26. Nahar, S.N.; Mohajeri, M.; Schmets, A.J.M.; Scarpas, A.; van de Ven, M.F.C.; Schitter, G. First observation of blending-zone morphology at interface of reclaimed asphalt binder and virgin bitumen. Transp. Res. Rec. J. Transp. Res. Board. 2013, 2370, 1-9. [CrossRef]

27. Willis, J.R.; Turner, O.; de Goes Padula, F.; Tran, N.; Julian, G. Effects of changing virgin binder grade and content on high reclaimed asphalt pavement mixture properties. Transp. Res. Rec. J. Transp. Res. Board. 2013, 2371, 66-73. [CrossRef]

28. Dony, A.; Colin, J.; Bruneau, D.; Drouadainc, I.; Navaro, J. Reclaimed asphalt concretes with high recycling rates: Changes in reclaimed binder properties according to rejuvenating agent. Constr. Build. Mater. 2013, 41, 175-181. [CrossRef]

29. Lin, J.; Guo, P.; Xie, J.; Wu, S.; Chen, M. Effect of rejuvenator scaler materials on the properties of aged asphalt binder. J. Mater. Civ. Eng. 2013, 25, 829-835. [CrossRef]

30. Čygas, D.; Mučinis, D.; Sivilevičius, H.; Abukauskas, N. Dependence of the recycled asphalt mixture physical and mechanical properties on the grade and amount of rejuvenating bitumen. Balt. J. Road Bridge Eng. 2011, 6, 124-134. [CrossRef]

31. Huang, S.-C.; Qin, Q.; Grimes, W.R.; Pauli, A.T.; Galer, R. Influence of Rejuvenators on the Physical Properties of RAP Binders. J. Test. Eval. 2015, 43, 594-603. [CrossRef]

32. Shirodkar, P.; Mehta, Y.; Nolan, A.; Sonpal, K.; Norton, A.; Tomlison, C.; Dubois, E.; Sullivan, P.; Sauber, R. A study to determine the degree of partial blending of reclaimed asphalt pavement (RAP) binder for high RAP hot mix asphalt. Constr. Build. Mater. 2011, 25, 150-155. [CrossRef]

33. Karlsson, R.; Isacsson, U. Material-related aspects of asphalt recycling—State-of-art. J. Mater. Civ. Eng. 2006, 18, 81-92. [CrossRef]

34. Wang, F.; Wang, Z.; Li, C.; Xiao, Y.; Wu, S.; Pan, P. The rejuvenating effect in hot asphalt recycling by mortar transfer ratio and image analysis. Materials 2017, 10, 574. [CrossRef] [PubMed]

35. Poulikakos, L.D.; dos Santos, S.; Bueno, M.; Kuentzel, S.; Hugener, M.; Partl, M.N. Influence of short and long-term aging on chemical, microstructural and macro-mechanical properties of recycled asphalt mixtures. Constr. Build. Mater. 2014, 51, 414-423. [CrossRef]

36. Huang, B.; Li, G.; Vukosavljevic, D.; Shu, X.; Egan, B. Laboratory investigation of mixing hot-mix asphalt with reclaimed asphalt pavement. Transp. Res. Rec. J. Transp. Res. Board. 2005, 1929, 37-45. [CrossRef]

37. Bražiūnas, J.; Sivilevičius, H.; Virbickas, R. Dependences of SMA mixture and its bituminous binder properties on bitumen batching system, mixing time and temperature on asphalt mixing plant. J. Civ. Eng. Manag. 2013, 19, 862-872. [CrossRef]

38. Vislavičius, K.; Sivilevičius, H. Effect of reclaimed asphalt pavement gradation variation on the homogeneity of recycled hot-mix asphalt. Arch. Civ. Mech. Eng. 2013, 13, 345-353. [CrossRef] 
39. Aurangzeb, Q.; Al-Qadi, I.L.; Abuawad, I.M.; Pine, W.J.; Trepanier, J.S. Achieving desired volumetrics and performance for mixtures with high percentage of reclaimed asphalt pavement. Transp. Res. Rec. J. Transp. Res. Board. 2012, 2294, 34-42. [CrossRef]

40. Sivilevičius, H.; Vislavičius, K.; Bražiūnas, J. Technological and economic design of asphalt mixture composition based on optimization methods. Technol. Econ. Dev. Econ. 2017, 23, 627-648. [CrossRef]

41. Valdés, G.; Pérez-Jiménez, F.; Miró, R.; Martínez, A.; Botella, R. Experimental study of recycled asphalt mixtures with high percentages of reclaimed asphalt pavement (RAP). Constr. Build. Mater. 2011, 25, 1289-1297. [CrossRef]

42. Mučinis, D.; Sivilevičius, H.; Oginskas, R. Factors determining the inhomogeneity of reclaimed asphalt pavement and estimation of its components content variation parameters. Balt. J. Road Bridge Eng. 2009, 4, 69-79. [CrossRef]

43. Mogawer, W.S.; Austerman, A.J.; Bonaquist, R. Determining the influence of plant type and production parameters on performance of plant-produced reclaimed asphalt pavement mixtures. Transp. Res. Rec. J. Transp. Res. Board. 2012, 2268, 71-81. [CrossRef]

44. Silva, H.M.R.D.; Oliveira, J.R.M.; Jesus, C.M.G. Are totally recycled hot mix asphalts a sustainable alternative for road paving? Resour. Conserv. Recycl. 2012, 60, 38-48. [CrossRef]

45. Zhao, S.; Huang, B.; Shu, X.; Woods, M.E. Quantitative Characterization of Binder Blending. Transp. Res. Rec. J. Transp. Res. Board. 2015, 2506, 72-80. [CrossRef]

46. Babtista, A.M.; Picado-Santos, L.G.; Capitão, S.D. Design of hot-mix recycled asphalt concrete produced in plant without preheating the reclaimed material. Int. J. Pavement Eng. 2013, 14, 95-102. [CrossRef]

47. DeDene, C.D.; Voller, V.R.; Marasteanu, M.O.; Dave, E.V. Calculation of particle heating times of reclaimed asphalt pavement material. Road Mater. Pavement Des. 2014, 15, 721-732. [CrossRef]

48. National Cooperative Highway Research Program (NCHRP). A Manual for Design of Hot Mix Asphalt with Commentary. National Cooperative Highway Research Program. Transportation Research Board of the National Academics; NCHRP Report 673; NCHRP: Washington, DC, USA, 2011; p. 273.

49. Ma, T.; Huang, X.; Zhao, Y.; Zhang, Y.; Wang, H. Influences of preheating temperature of RAP on properties of hot-mix recycled asphalt mixture. J. Test. Eval. 2016, 44, 762-769. [CrossRef]

50. Baroux, R. Recyclage des enrobés bitumineux en centrale d'enrobage. Les problémes de matériel. Bulletin de Liaison des Ratoires des Ponts et Chaussées 1980, 105, 98-102. 